\title{
Atraumatic non-distorting pyloric sphincter pressure studies
}

\author{
A J MCSHANE,* C O’MORAIN, J R LENNON, J B COAKLEY, AND B G ALTON \\ From the Gastroenterology Unit, Mater Misericordiae Hospital, Dublin, and the Department of \\ Anatomy, University College Dublin, Dublin, Ireland
}

SUMMARY Conflicting claims have been made regarding the physiological characteristics of the pyloric sphincter. Pyloric sphincter pressures were studied in 32 patients under basal conditions, after stimulation with $\mathrm{HCl}$ and posture changes. At gastroscopy a $2 \mathrm{~mm}$ diameter manometer catheter was placed in the duodenum and three to five hours later the catheter was withdrawn slowly with continuous manometry. Lower oesophageal sphincter pressures fell within the expected range but there was no definite evidence of a pressure barrier at the pylorus in any group of patients. The technique caused no patient discomfort and minimal distortion of the region under study, indicating that the pylorus is usually patent with a lumenal diameter greater than $2 \mathrm{~mm}$.

Despite its striking anatomical structure, evidence that the pylorus functions as a physiological sphincter remains conflicting. Some recent studies ${ }^{2}$ have shown that the pylorus functions as a physiological sphincter responding to various stimuli, but these findings were not substantiated by Kaye and his colleagues ${ }^{3}$ who used very similar techniques.

These conflicting observations prompted us to reevaluate pyloric sphincter pressure responses under resting basal conditions and under varying stimuli. A single fine manometer catheter was used to minimise pyloric distortion and patient discomfort. The catheter was placed endoscopically and its position confirmed fluoroscopically.

\section{Methods}

The recording catheter (Kifa 17.887-7; outside diameter $2 \mathrm{~mm}$ ) was modified over a flame, the end being sealed and made into a sprung pig-tailed loop for safe introduction. Two diametrically opposite openings, approximately $1 \mathrm{~mm}$ diameter, were punched $12 \mathrm{~cm}$ proximal to the looped end. After routine gastroscopy the catheter was passed down the biopsy channel of the gastroscope (Olympus GIF-K) into the distal duodenum, with the aid of a guide wire (Cook TSF 38:300BH). On emerging from the end of the gastroscope the catheter re-

-Address for correspondence and requests for reprints: Alan J McShane, Gastroenterology Unit, Mater Misericordiae Hospital, Dublin 7, Ireland.

Received for publication 4 June 1980 assumed its pig-tail loop. Three to five hours after gastroscopy the position of the catheter was checked fluoroscopically. It was then connected to a physiological pressure transducer (Bell and Howlett 4-422-0001/2) and perfused with water at a rate of $0.26 \mathrm{ml} / \mathrm{min}$, using a syringe pump (Sage model 355 ). The pressure changes were recorded on a Devices M19, 6 channel system. The catheter was continuously withdrawn at a slow fixed rate $(0.79 \mathrm{~cm} / \mathrm{min})$ using a motor.

Informed consent was obtained from 32 patients randomly selected from the Gastroscopy Clinic and divided into four groups. All had fasted overnight. Diazepam $10-20 \mathrm{mg}$ intravenously was used for sedation.

GROUP I

(Seven male, four female; mean age 51 years.) Resting pyloric and lower oesophageal sphincter pressures were recorded. The catheter openings were shown fluoroscopically to be in the fourth part of the duodenum and the catheter then withdrawn continuously to the mid-oesophagus.

As the pressure recordings from parts III and IV of the duodenum in group I were unremarkable, it was decided to simplify the procedure, starting catheter withdrawal when the catheter openings were in the mid-second part of the duodenum in groups II, III, and IV.

GROUP II

(Five male, six female; mean age 48.8 years.)

Resting pyloric pressures were studied starting 
withdrawal in the mid-second part of the duodenum and stopping withdrawal whenever any deviation of pressure from the base line was recorded and then checking the position fluoroscopically before restarting.

\section{GROUP III}

(Two male, three female; mean age 44.3 years.) The effect of $\mathrm{HCl}$ was studied, pressure recordings again starting in the mid-second part of the duodenum. A bolus of $50 \mathrm{ml}$ O.IN $\mathrm{HCl}$ was delivered over one minute via the manometer catheter and withdrawal started. During withdrawal, perfusion of the catheter with $\mathrm{O} . \mathrm{IN} \mathrm{HCl}$ was continued while pressure was monitored continuously.

\section{GROUP IV}

(Four male, one female; mean age 48.4 years.) The effect of position was assessed by continuous pressure monitoring while the catheter was withdrawn by motor into the stomach with the patient lying on his right hand side. The catheter had been previously positioned fluoroscopically in the middle of the second part of the duodenum.

\section{Results}

\section{GROUP I}

(Endoscopic diagnosis: no abnormality-six patients; duodenal ulceration-four patients; hiatus hernia and oesophagitis - one patient. See Table.) No rise in pressure in the region of the pylorus was observed in eight patients, while three patients showed pressure rises $(0.4,0.4$, and $0.8 \mathrm{kPa}(3,3$, and $6 \mathrm{mmHg}$ )). Lower oesophageal sphincter pressure recordings showed values ranging from $1.46-4.4 \mathrm{kPa} \quad(11-33 \mathrm{mmHg}$ ) (mean $2.63 \mathrm{kPa}$ $(19.7 \mathrm{mmHg}) ; \mathrm{SD} \pm 1.035(7.761))$.

\section{GROUP II}

(Endoscopic diagnosis: no abnormality-eight patients; duodenal ulceration-two patients; pylorospasm-one patient.) Ten of the 11 patients in this group showed no rise in pressure in the pyloric region. In one patient (endoscopic diagnosis: no abnormality) there was a $1.6 \mathrm{kPa}(12 \mathrm{mmHg})$ rise in pressure at the pyloric region lasting a total of 10 seconds, corresponding to withdrawal length of $1.3 \mathrm{~mm}$. After reintroduction and repeat withdrawal a pressure rise of $0.8 \mathrm{kPa}(6 \mathrm{mmHg})$ was found in the same region. Withdrawal was stopped and the pressure fell to base line after three minutes, remaining there during 17 minutes continued observation. The catheter was then withdrawn into the stomach, and no further pressure rise was obtained.

\section{GROUP III}

(Endoscopic diagnosis: no abnormality-all five patients.) No rise in pressure was recorded in the pyloric regions of the five patients after intraduodenal infusion of $\mathrm{HCl}$.

\section{GROUP IV}

(Endoscopic diagnosis: no abnormality-three patients; pylorospasm-one patient; atrophic gastritis -one patient.) No rise in pressure was recorded in the pyloric region of the five patients studied in the right lateral position.

\section{Discussion}

The aim of this study was to devise a method of studying the pylorus under truly basal conditions, with a totally relaxed patient and a recording catheter which caused minimal distortion of the area under study. The Kifa catheter, designed pri-

Table Group 1. Pyloric and lower oesophageal sphincter pressures

\begin{tabular}{|c|c|c|c|c|c|c|}
\hline \multirow[b]{2}{*}{ Patient } & \multirow[b]{2}{*}{ Endoscopic diagnosis } & \multicolumn{5}{|l|}{ Pressures } \\
\hline & & $\begin{array}{l}\text { Pyloric region } \\
(\mathrm{kPa})\end{array}$ & $(\mathrm{mmHg})$ & & $\begin{array}{l}\text { Lower oesophageal sph } \\
(k P a)\end{array}$ & $\begin{array}{l}\text { hincter } \\
(\mathrm{mmHg})\end{array}$ \\
\hline 1 & NAD & 0.0 & & & $2 \cdot 4$ & 18 \\
\hline 2 & NAD & $0 \cdot 0$ & & & 2.67 & 20 \\
\hline 3 & DU & $0 \cdot 0$ & & & $4 \cdot 4$ & 33 \\
\hline 4 & DU & 0.0 & & & $2 \cdot 4$ & 18 \\
\hline 5 & DU & $0 \cdot 0$ & & & Not obtained & \\
\hline \multirow[t]{2}{*}{6} & NAD & 0.8 & 6 & & $2 \cdot 4$ & 18 \\
\hline & & (Duodenal acti & rked) & & & \\
\hline 7 & DU & $0 \cdot 0$ & & & $4 \cdot 0$ & 30 \\
\hline 8 & NAD & 0.0 & & & 1.46 & 11 \\
\hline 9 & $\begin{array}{l}\mathrm{HH} \\
\text { and oesophagitis }\end{array}$ & $0 \cdot 4$ & 3 & & 1.6 & 12 \\
\hline 10 & NAD & 0.4 & 3 & & 3.46 & 26 \\
\hline \multirow[t]{2}{*}{11} & NAD & 0.0 & & & $1 \cdot 46$ & \\
\hline & & & & $\begin{array}{l}\text { Mean: } \\
\text { SD }\end{array}$ & $\begin{array}{l}2.63 \\
\pm 1.035\end{array}$ & $\begin{array}{l}19 \cdot 7 \\
\pm 7 \cdot 761\end{array}$ \\
\hline
\end{tabular}


marily for angiography, could be easily introduced through the biopsy channel of the gastroscope, being flexible but firm and non-compressible. This latter property ensured that only pressure at the two distal openings was recorded. The method used is sensitive and accurate and lower oesophageal sphincter pressures are within the expected range. ${ }^{45}$ However, it was not possible to demonstrate any significant zone of pressure change at the pylorus either in the basal or stimulated state.

The method was well accepted by the patients and the very slow catheter withdrawal, starting three to five hours after endoscopy, resulted in the patient being unaware of its movement. This is in contrast with the technique of Fisher and Cohen ${ }^{1}$ and Valenzuela and his colleagues ${ }^{2}$ who withdrew the catheter shortly after intubation, at a time when nervous stimuli induced by intubation might have affected the sphincter tone.

Catheter assemblies used up to the present have had wide diameters, and that of Fisher and Cohen $^{1}$ was nearly three times the diameter of that in the present study. It has been shown in $\operatorname{dogs}^{6}$ that the larger the outside diameter of the pressuredetecting unit, the greater the pressures recorded at the pylorus, with the implication that the zones of high pressure recorded in some studies ${ }^{12}$ may have been due to muscle excitation and resistance to stretch and not a true reflection of basal pyloric sphincter tone. The use of the Kifa catheter avoids such mechanical stimulation of the sphincter.

Trauma to the pylorus from the gastroscope is unlikely to have affected the pressure recording, as manometry was carried out at least three hours after gastroscopy, and lower oesophageal sphincter pressures were within the expected range. It is possible, but unlikely, that the intravenous premedication with diazepam, given at least three hours before manometry could have affected the results. Lower oesophageal sphincter pressures were unaffected and there is no evidence to suggest that the pyloric region should have been affected.

Intraduodenal $\mathrm{HCl}$, a potent releaser of secretin and cholecystokinin, ${ }^{7}$ has been claimed to be a potent stimulator of the pyloric sphincter through these hormones. ${ }^{12}$ Nevertheless, we were unable to document such an effect with intraduodenal $\mathrm{HCl}$, the sphincter remaining patent with a lumenal diameter greater than $2 \mathrm{~mm}$.
Based on evidence from studies carried out on the dog's stomach, ${ }^{3}$ it has been postulated that the right lateral position used in the studies showing a pressure zone might produce artefactual pressure from kinking at the gastroduodenal junction in this position. The present results do not support this conclusion and recordings from patients in both supine and right lateral positions indicated that position does not affect pressure.

The present results show that the pyloric sphincter remains patent with a lumenal diameter greater than $2 \mathrm{~mm}$ under fasting basal conditions, on lying on the right hand side and after introduodenal perfusion with O.IN HCl. These findings fit with the postulation that the pylorus functions as a filter pump, ${ }^{8}$ filtering particles at least greater than $2 \mathrm{~mm}$ in diameter, and allowing fluid and chyme into the duodenum continuously, and is in agreement with the usual gastroscopic finding of a patent plyorus. ${ }^{910}$

\section{References}

${ }^{1}$ Fisher R, Cohen S. Physiological characteristics of the human pyloric sphincter. Gastroenterology 1973; 64: 67-75.

${ }^{2}$ Valenzuela JE, Defilippi C, Csendes A. Manometric studies on the human pyloric sphincter: effect of cigarette smoking, metoclopramide and atropine. Gastroenterology 1976; 70: 481-3.

${ }^{3}$ Kaye MD, Mehta SJ, Showalter JP. Manometric studies of the human pylorus. Gastroenterology 1976; 70: 477-80.

${ }^{4}$ Fyke FR, Code CF, Schlegel JF. The gastroesophageal sphincter in healthy human beings. Gastroenterologia (Basel) 1956; 86: 145-50.

${ }^{5}$ Kaye MD, Showalter JP. Manometric configuration of the lower esophageal sphincter in normal human subjects. Gastroenterology 1971 ; 61 : 213-23.

${ }^{6}$ Brink BM, Schlegel JF, Code CF. The pressure profile of the gastroduodenal junctional zone in dogs. Gut 1965; 6: 163-71.

'Fisher RS, Lipshutz W, Cohen S. The hormonal regulation of pyloric sphincter function. $J$ Clin Invest 1973; 52: 1289-96.

${ }^{8}$ Atkinson M, Edwards DAW, Honour AJ, Rowlands EN. Comparison of cardiac and pyloric sphincters, a manometric study. Lancet 1957; 2 : 918-22.

${ }^{9}$ Rider JA, Moeller HC, Puletti EJ. Gastroscopic observation of the dynamic anatomy of the antrum and pylorus. Gastrointest Endosc 1967; 14: 100-1.

${ }^{10}$ Blackwood WD. Pylorus identification. Gastroenterology 1969; 57: 163-7. 